\title{
ANALYSIS OF INFLUENCE OF HEAT TRANSFER CONDITIONS ON THE UPPER COVER TO HEAT TRANSFER IN THERMOSYPHON
}

\author{
Alexander Krasnoshlykov ${ }^{1, *}$ \\ ${ }^{1}$ National Research Tomsk Polytechnic University, 634050 Tomsk, Russia
}

\begin{abstract}
Numerical analysis of thermal conditions of a two-phase closed thermosyphon using the software package ANSYS FLUENT has been carried out. Temperature distributions at various heat transfer conditions on upper cover and different heat flow on bottom cover of thermosyphon have been obtained.
\end{abstract}

\section{Introduction}

Lithium-ion batteries play an important role as an source energy in a variety of applications (motor transport, aviation and space equipment) and have prospects for development through the use of less toxic materials, low weight, high energy and power density $[1,2]$. However, a major obstacle to wide use of batteries of this type is the flammability and low performance at increasing temperature due to thermal runaway $[1,2]$.

Thermal runaway of the battery is the effect which occurs when the electrolyte temperature increases and the current flowing through the battery can rise to values approaching the short-circuit current [2]. Thermal runaway is able to affect the safety of the use of vehicles (e.g., aircraft [1]). Thermal runaway occurs at a combination of factors: the electrolyte temperature rise due to insufficient battery heat exchange with the environment; low level of electrolyte in the battery cell; aging active electrode mass [2].

Therefore, to maintain the temperature of the battery pack in a safe range for it is necessary to intensify the heat transfer from the outer surfaces.

Currently, system regulation thermal mode of batteries on the basis of the closed twophase thermosiphons does not apply [3, 4]. Nowadays studies of thermal conditions thermosyphons at work with heat fluxes and the geometrical dimensions of the batteries used in vehicles (eg cars, aircrafts) has not been carried out.

It should be noted that the heat transfer characteristics of the two-phase closed thermosyphon affects a large number of factors [4]. One such factor is the heat transfer coefficient on the top cover of the thermosyphon. Experimental study of the regularities of heat transfer in thermosyphons often is problematic due to the multi-dimensionality of the factor space.

*Corresponding author: krasnas@tpu.ru 
Mathematical modeling is the most rational method of investigation of thermal and hydrodynamic processes in thermosyphon.

There are mathematical models of physical processes occurring in the thermosyphon [5, 6]. But these models describe the work processes of heat transfer systems with a fairly significant assumptions on the mechanism of heat transfer. For example, in [5] accepted a model of the boundary layer flow in the vapor channel, and [6] discusses flow regimes at low speeds blowing vapor of the refrigerant from the heated surface and not taken into account a number of processes taking place in the vapor and liquid phases of the working fluid.

The purpose of work is mathematical modeling of heat transfer in two-phase closed thermosyphon at various conditions heat transfer on the top cover.

Accepted following scheme of the investigated process of heat transfer. The heat released during the technical elements of the system (e.g., battery) is supplied to the surface of the bottom cover of the thermosyphon (fig.1), as a result of the thermal conductivity of the coolant temperature increases. Near the surface of evaporation increases vapor pressure $(\mathrm{P})$, vapor is moves upward and condenses on the inner surface of the top cover with the release of latent heat. The film of condensate flows down on the vertical walls of thermosyphon to heating zone.

\section{Formulation of problem}

Chart of the closed thermosyphon rectangular cross section considered in figure1.

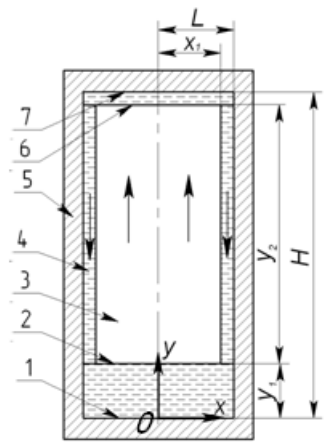

Fig. 1. Schematic diagram of the thermosyphon: 1 - bottom cover; 2 - surface evaporation; 3 - vapor flow; 4 - liquid film; 5 - vertical wall; 6 - condensing surface; 7 - top cover.

The equations of continuity, momentum and energy to be solved for the steam and the liquid film in the study area are of the form:

$$
\begin{gathered}
\frac{\partial \rho}{\partial t}+\frac{\partial(\rho u)}{\partial x}+\frac{\partial(\rho v)}{\partial y}=0 \\
\frac{\partial \rho_{1} u_{1}}{\partial t}+\frac{\partial\left(\rho_{1} u_{1} u_{1}\right)}{\partial x}+\frac{\partial\left(\rho_{1} v_{1} u_{1}\right)}{\partial y}=\rho_{1} g_{x}-\frac{\partial P_{1}}{\partial x}+\frac{\partial}{\partial x}\left(\mu_{1} \frac{\partial u_{1}}{\partial x}\right)+\frac{\partial}{\partial y}\left(\mu_{1} \frac{\partial u_{1}}{\partial y}\right) \\
\frac{\partial \rho_{1} v_{1}}{\partial t}+\frac{\partial\left(\rho_{1} u_{1} v_{1}\right)}{\partial x}+\frac{\partial\left(\rho_{1} v_{1} v_{1}\right)}{\partial y}=\frac{\partial P_{1}}{\partial y}+\frac{\partial}{\partial x}\left(\mu_{1} \frac{\partial v_{1}}{\partial x}\right)+\frac{\partial}{\partial y}\left(\mu_{1} \frac{\partial v_{1}}{\partial y}\right) \\
\frac{\partial \rho_{2} u_{2}}{\partial t}+\frac{\partial\left(\rho_{2} u_{2} u_{2}\right)}{\partial x}+\frac{\partial\left(\rho_{2} v_{2} u_{2}\right)}{\partial y}=\rho_{2} g_{x}-\frac{\partial P_{2}}{\partial x}+\frac{\partial}{\partial x}\left(\mu_{2} \frac{\partial u_{2}}{\partial x}\right)+\frac{\partial}{\partial y}\left(\mu_{2} \frac{\partial u_{2}}{\partial y}\right)
\end{gathered}
$$




$$
\begin{gathered}
\frac{\partial \rho_{2} v_{2}}{\partial t}+\frac{\partial\left(\rho_{2} u_{2} v_{2}\right)}{\partial x}+\frac{\partial\left(\rho_{2} v_{2} v_{2}\right)}{\partial y}=\frac{\partial P_{2}}{\partial y}+\frac{\partial}{\partial x}\left(\mu_{2} \frac{\partial v_{2}}{\partial x}\right)+\frac{\partial}{\partial y}\left(\mu_{2} \frac{\partial v_{2}}{\partial y}\right) \\
\rho_{1} C_{p 1}\left(\frac{\partial T_{1}}{\partial t}+u_{1} \frac{\partial T_{1}}{\partial x}+v_{1} \frac{\partial T_{1}}{\partial y}\right)=\lambda_{1}\left(\frac{\partial^{2} T_{1}}{\partial x^{2}}+\frac{\partial^{2} T_{1}}{\partial y^{2}}\right) \\
\rho_{2} C_{p 2}\left(\frac{\partial T_{2}}{\partial t}+u_{2} \frac{\partial T_{2}}{\partial x}+v_{2} \frac{\partial T_{2}}{\partial y}\right)=\lambda_{2}\left(\frac{\partial^{2} T_{2}}{\partial x^{2}}+\frac{\partial^{2} T_{2}}{\partial y^{2}}\right) .
\end{gathered}
$$

Where $u, v$ - the velocity components in the projection on the axis $x, y$, respectively; $P$ - pressure; $T$ - temperature; $\rho$ - density; $x, y$ - Cartesian coordinates; $t$ - time; $C p$ - heat capacity; $g$ - acceleration of gravity; $\lambda$ - coefficient of thermal conductivity; $\mu$ - dynamic viscosity; indices 1,2 - properties of the liquid and vapor.

The initial conditions for the system of equations (1-7) are given in the form:

$u(x, y)=0 ; T(\mathrm{x}, \mathrm{y})=T_{0} ; P(\mathrm{x}, \mathrm{y})=P_{0}$.

The boundary conditions for the equations (1-7) have the form:

$$
\begin{gathered}
x=0,0<y<H, \quad \frac{\partial T_{2}}{\partial x}=0 ; \quad \frac{\partial u_{2}}{\partial x}=0, \frac{\partial v_{2}}{\partial x}=0, \\
x=L, 0 \leq y \leq H, \quad \lambda_{1} \frac{\partial T_{1}}{\partial x}=0 ; \quad u_{1}=v_{1}=0, \\
x=x_{1}, y_{1} \leq y \leq y_{1}+y_{2},\left\{\begin{array}{l}
T_{1}=T_{2} \\
\lambda_{1} \frac{\partial T_{1}}{\partial x}=\lambda_{2} \frac{\partial T_{2}}{\partial x} ; \quad\left\{\begin{array}{l}
u_{1}=u_{2}=0 \\
v_{2}=0
\end{array}, \frac{\partial v_{1}}{\partial x}=0,\right.
\end{array}\right. \\
y=y_{1}, 0 \leq x \leq x_{1},\left\{\begin{array}{l}
T_{1}=T_{2} \\
\lambda_{1} \frac{\partial T_{1}}{\partial y}=\lambda_{2} \frac{\partial T_{2}}{\partial y}-Q_{e} w_{e}-v_{2} C_{p} \rho\left(T_{2}-T_{0}\right)
\end{array}, v_{2}=\frac{w_{e}}{\rho_{2}}, v_{1}=\frac{w_{e}}{\rho_{1}},\right. \\
y=y_{1}+y_{2}, 0 \leq x \leq x_{1},\left\{\begin{array}{l}
T_{2}=T_{1} \\
\lambda_{2} \frac{\partial T_{2}}{\partial y}=\lambda_{1} \frac{\partial T_{1}}{\partial y}+Q_{c} w_{c}+v_{2} C_{p} \rho\left(T_{1}-T_{0}\right)
\end{array}, v_{1}=\frac{w_{c}}{\rho_{1}}, v_{2}=0,\right. \\
y=0,0 \leq x \leq L, \lambda_{1} \frac{\partial T_{1}}{\partial y}=q_{h}, u_{1}=v_{1}=0,
\end{gathered}
$$

where $\alpha$ - heat transfer coefficient, $\mathrm{W} /\left(\mathrm{m}^{2} \cdot \mathrm{K}\right)$.

Mathematical modeling of the task carried out in the package ANSYS FLUENT software. Mass rate of evaporation and condensation were calculated according to the formula [7]:

$$
w_{c}=\beta \sqrt{\frac{M}{2 \pi R T_{H}}}\left(P_{2}-P_{H}\right) \text {, }
$$

where $P_{H}$ - saturation pressure; $T_{H}$ - saturation temperature; $R$ - universal gas constant; $M$ - molar weight; $\beta$ - accommodation coefficient. 


\section{Results and Discussion}

Numerical simulation of heat transfer in a two-phase closed thermosyphon rectangular cross section (figure 1) with the following geometric dimensions: transverse dimension $L=$ $0.05 \mathrm{~m}$; the longitudinal dimension $H=0.3 \mathrm{~m}$ has been carried out. To investigate the effect of heat transfer conditions on the performance of the thermosyphon have been taken the following variations the heat transfer coefficient $(\alpha)$ on the top cover: $9.6 \mathrm{~W} /\left(\mathrm{m}^{2} \cdot \mathrm{K}\right) ; 15.6$ $\mathrm{W} /\left(\mathrm{m}^{2} \cdot \mathrm{K}\right) ; 25.6 \mathrm{~W} /\left(\mathrm{m}^{2} \cdot \mathrm{K}\right)$. The heat flux density on the lower cover of thermosyphon in section $\mathrm{y}=0: 1.1 \cdot 10^{4} \mathrm{~W} / \mathrm{m}^{2} ; 1.7 \cdot 10^{4} \mathrm{~W} / \mathrm{m}^{2} ; 2.3 \cdot 10^{4} \mathrm{~W} / \mathrm{m}^{2}$. Water was considered as a working liquid.

The obtained distribution of temperature show that at $q_{h}=1.1 \cdot 10^{4} \mathrm{~W} / \mathrm{m}^{2}$ (fig. 2a) and the heat transfer coefficient $\alpha=9.6 \mathrm{~W} /\left(\mathrm{m}^{2} \cdot \mathrm{K}\right.$ ) (curve 1) the difference $\mathrm{T}$ between the lower and upper covers of thermosyphon is about $6^{\circ} \mathrm{K}$. At changing $\alpha$ the top cover in the range of $15.6 \mathrm{~W} /\left(\mathrm{m}^{2} \cdot \mathrm{K}\right.$ ) (curve 2 ) to $25.6 \mathrm{~W} /\left(\mathrm{m}^{2} \cdot \mathrm{K}\right.$ ) (curve 3 ) the temperature difference $(\Delta \mathrm{T})$ in the test area is greater than $\alpha=9.6 \mathrm{~W} /\left(\mathrm{m}^{2} \cdot \mathrm{K}\right)$ and is $7.5 \mathrm{~K}$ and $8 \mathrm{~K}$, due to the intense outflow of heat on the top cover of the thermosyphon.

Figures 2 and 3 show that increasing the heat flow density in the range of $1.1 \cdot 10^{4} \mathrm{~W} / \mathrm{m}^{2}$ to $2.3 \cdot 10^{4} \mathrm{~W} / \mathrm{m}^{2}$ leads to an increase $\Delta T$ by about $2^{\circ} \mathrm{K}$. At $q_{h}=1.7 \cdot 10^{4} \mathrm{~W} / \mathrm{m}^{2}$ on the bottom cover of the study device (fig. $2 \mathrm{~b}$ ) temperature difference is $4^{\circ} \mathrm{K}, 5.5^{\circ} \mathrm{K}, 6^{\circ} \mathrm{K}$, according to variants the heat transfer coefficients on the top cover, and at $q_{h}=2.3 \cdot 10^{4} \mathrm{~W} / \mathrm{m}^{2}$ (fig. 3 ) $2^{\circ} \mathrm{K}, 3.5^{\circ} \mathrm{K}, 4^{\circ} \mathrm{K}$.

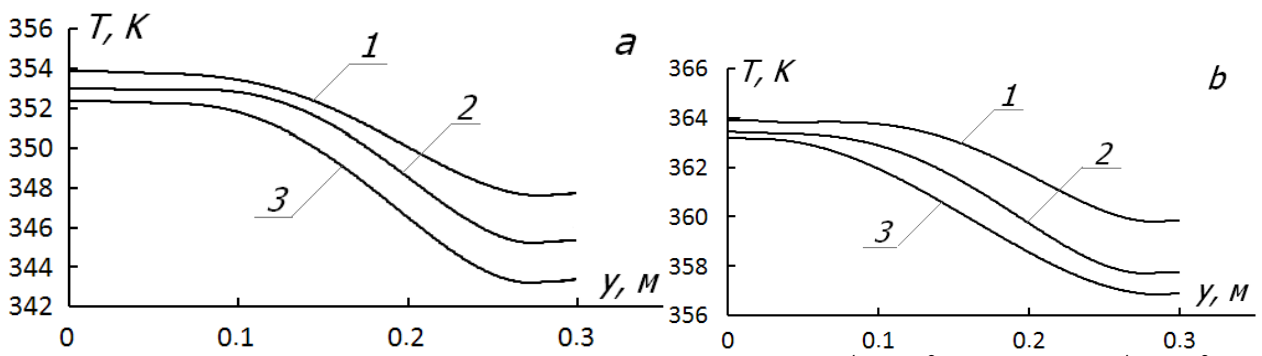

Fig. 2. The temperature distribution in the direction $y: \mathbf{a}-q_{h}=1.1 \cdot 10^{4} \mathrm{~W} / \mathrm{m}^{2} ; \mathbf{b}-q_{h}=1.7 \cdot 10^{4} \mathrm{~W} / \mathrm{m}^{2}$. $1-\alpha=9.6 \mathrm{~W} /\left(\mathrm{m}^{2} \cdot \mathrm{K}\right) ; 2-\alpha=15.6 \mathrm{~W} /\left(\mathrm{m}^{2} \cdot \mathrm{K}\right) ; 3-\alpha=25.6 \mathrm{~W} /\left(\mathrm{m}^{2} \cdot \mathrm{K}\right)$.

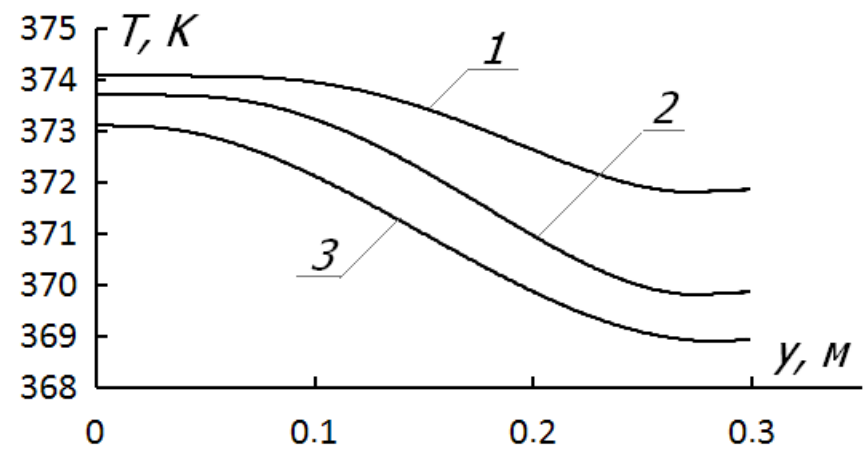

Fig. 3. The temperature distribution in the direction $y$ at $q_{h}=2.3 \cdot 10^{4} \mathrm{~W} / \mathrm{m}^{2}: 1-\alpha=9.6 \mathrm{~W} /\left(\mathrm{m}^{2} \cdot \mathrm{K}\right) ; 2-$ $\alpha=15.6 \mathrm{~W} /\left(\mathrm{m}^{2} \cdot \mathrm{K}\right) ; 3-\alpha=25.6 \mathrm{~W} /\left(\mathrm{m}^{2} \cdot \mathrm{K}\right)$. 


\section{Conclusion}

The dependence of the temperature difference between the upper and lower covers of a closed two-phase thermosyphon from different conditions of intensity heat transfer at the upper cover have been obtained. It is shown that an increase $\alpha$ in range $9.6-25.6 \mathrm{~W} /\left(\mathrm{m}^{2} \cdot \mathrm{K}\right)$ leads to an increase $\Delta \mathrm{T}$ to $2^{\circ} \mathrm{K}$.

\section{Acknowledgments}

The work was held within the research state assignment "Science" No. 13.1339.2014/K (Code of Federal Target Scientific and Technical Program 2.1410.2014).

\section{References}

1. T. Song, Y. Li, J. Song, Z. Zhang, Proc. Eng. 80 (2014)

2. D.A. Khrustalyov, Rechargeable batteries (Emerald, Moscow, 2003)

3. J.L.G. Oliveira, C. Tecchio, K.V. Paiva, M.B.H. Mantelli, R. Gandolfi, L.G.S. Ribeiro, Appl. Th. Eng. 79 (2015)

4. M.K. Bezrodnyi, I.L. Pioro, T.S. Kostyuk, Transfer processes in the two-phase thermosyphon systems (Kiev, 2005)

5. G.V. Kuznetsov, A.E. Sitnikov, High Temp. (2002)

6. G.V. Kuznetsov, M.A. Al-Ani, M.A. Sheremet, J. Eng. Thermoph. (2011)

7. Ansys Help. FLUENT Theory Guide 